\title{
Phytochemical properties and antioxidant activity of Echinops persicus plant extract: green synthesis of carbon quantum dots from the plant extract
}

\author{
Mohammad Ali Nasseri ${ }^{1} \cdot$ Hamideh Keshtkar ${ }^{1} \cdot$ Milad Kazemnejadi $^{1}$. Ali Allahresani ${ }^{1}$
}

Received: 11 November 2019 / Accepted: 10 March 2020 / Published online: 16 March 2020

(c) Springer Nature Switzerland AG 2020

\begin{abstract}
Echinops persicus is a species of Echinops that can be found in Europe and western Asia especially in Iran. In this paper, the phytochemical properties of Echinops persicus were thoroughly investigated and studied. In this way, total amounts of flavonoid, tannins, phenols, carotenoids, saponins, alkaloids, and anthocyanin were measured by various analytical methods. The major phenolic and flavonoid content was found in the root acetone and flower ethanolic extract of the plant. Also, major saponins and carotenoid contents was found in root and leaf of the plant. These measurements were also performed for root, leaf, and flower of the plant in various solvent extracts. The results indicated that Echinops persicus is a rich source of secondary metabolites. Also, the plant extract demonstrated a considerable antiradical activity, which evaluated qualitatively as well as quantitatively. The largest capacity to neutralize DPPH radicals was found for root water extract of Echinops persicus plant. Finally, the possibility of the plant extract was evaluated for the green preparation of carbon quantum dots (CQDs). As-prepared CQDs were characterized by TEM, HRTEM, UV-Vis, XRD, and EDX analyses.
\end{abstract}

Keywords Echinops persicus · Antioxidant · Secondary metabolites · Carbon quantum dots · Green preparation of CQDs

\section{Introduction}

Plants are the richest resource of pharmaceutical molecules, nutraceuticals, food supplements, and chemical frameworks for design of synthetic drugs [1]. They have involved different phytochemicals and enzymes as antioxidant defense to maintain the growth and metabolism system. Newly interest has been focused on natural antioxidants owing to side effects of synthetic antioxidants [2]. To this end, the study of medicinal plants is widely underway. For example, various therapeutic properties have been reported for Falcaria vulgaris [3], Allium saralicum [4,
5], Falcaria vulgaris [6], Stevia rebaudiana (bitter fraction) [7] etc.

Echinops persicus is a species of Echinops that its extract of Echinops persicus is traditionally used long time in Iran for the treatment of cough and constipation. This plant can be found in Europe and Western Asia especially in the east of Iran. It was used for the treatment of lung diseases as mucus or discounts, anti-cough and asthma therapy [8]. Other treatments such as suppress of depression, constipation and obesity, fever-reducing and balancing the digestive system, and as anti-cancer activity were also biological activities reported for this plant [9].

Electronic supplementary material The online version of this article (https://doi.org/10.1007/s42452-020-2466-0) contains supplementary material, which is available to authorized users.

Mohammad Ali Nasseri, manaseri@birjand.ac.ir | ${ }^{1}$ Department of Chemistry, Faculty of Science, University of Birjand, P. O. Box 97175-615, Birjand, Iran. 
Saponins are a group of active compounds with numerous biological properties that are synthesized from secondary metabolites. They can be found in a large number of plants and crops. It has the least toxic effect on non-target organisms and the environment, and plays an important role in maintaining and developing sustainable crops [10]. According to the hypotheses presented in the literature, saponins have a protective-inhibitory activity against the plant and cause gastrointestinal problems, disruption of peeling, and cytotoxicity in pests. For this reason, these herbal compounds can be sprayed or selected with more saponins varieties as a very effective tool in integrated management programs to preserve agricultural and horticultural products. It also has no carcinogenic, mutagenic and glandular properties and is considered as a safe pesticide [11].

Flavonoids are among the secondary metabolites of the plant that play an important role in human health, due to their antioxidant activity. Recently, flavonoids were used as a reducing agent for the preparation of biocompatible AgNPs, because they have relatively low affinity to the metal surface (they do not contain $\mathrm{S}$ or $\mathrm{N}$ atom in their structures), which means adsorption of metal ions can be quite simple [12].

Anthocyanins play the role of dye in plants; which plants in red, orange and black colors have the highest amount of anthocyanins. Today, anthocyanins are used as a dye in food, cosmetics and health industries [13]. Tannin is one of the secondary metabolites that cause leather-like skin in plants and fruits. Tannins have an electronic structure that exhibits a synergistic effect in the photocatalytic process [14]. In the food industry tannins are used to clarify wine, beer, and fruit juices. Other industrial uses of tannins include textile dyes, as antioxidants in the fruit juice, beer, and wine industries, and as coagulants in rubber production. Tannins have also anti-tumor, antibacterial and antiviral activities. For example, certain tannins can selectively inhibit HIV replication [14, 15].

Carotenoids are the most widespread class of isoprenoid pigments that are synthesized by photosynthetic organisms in plants, some non-photosynthetic bacteria and fungi [16]. Since animals are unable to synthesize carotenoids, they need to be obtained from plants. Carotenoids also have wide application in cosmetic products due to their photo protection properties against UV radiation. There are over 600 known carotenoids that can be classified into two groups of xanthophyll and carotenes contain only a hydrocarbon chain without any functional group, including $\beta$-carotene and lycopene $[16,17]$.

The use of nanotechnology in all sciences, including medicine, petrochemical, pharmaceutical, materials sciences, defense industries, electronics, quantum computing, etc., has made nanotechnology a major scientific and industrial challenge for the world [18]. Various methods have been developed for this purpose. The preparation of green nanoparticles using plant extracts is a method that has attracted much attention in recent decades due to environmental issues [19, 20]. Cu [21], Ag [18], Ti [19], and $\mathrm{Au}[20]$ are among the NPs successfully prepared from plant extracts. In recent years, there is raising research attention to find methods aimed to produce eco-friendly nanoparticles, which does not use toxic materials [22]. Carbon quantum dots are among the nanoparticles that are considered today because of their extraordinary and unique properties [23]. They are a new generation of nano carbon structures (ex. fullerene, carbon nano tubes, graphene), which has attracted much attention due to its high resistance to light exposure, biocompatibility, low toxicity, high activity toward blue dye removal from the water, economic cost and its abundance in raw materials in nature [24]. Quantum dots synthesized by green methods have many applications in various sciences [23]. For example, CQDs prepared by chitosan (as a precursor) are used in the manufacture of electronic devices [25]. Quantum dots synthesized using glucose and tree date palm are other examples of green synthesis of CQDs that have been used for the biological imaging in the body of living things [26] and luminous diodes respectively [27]. Recently, Yang et al., reported the preparation of high-fluorescence-doped quantum dots from glucose and showed their application in the detection of cancer cells in mice [28].

In this study, secondary metabolites of Echinops persicus were studied and quantified in various extractions. In the following, the antiradical/ antioxidant activity of the plant in various organs was measured qualitatively as well as quantitatively. Finally, the green preparation of CQDs was successfully accomplished by the aqueous extract of the plant.

\section{Experimental}

\subsection{Instruments}

Fluorescence spectroscopy analyses were performed on a JASCO FP-6500 spectrofluorometer. Fourier transform infrared (FTIR) analyses for the samples were taken on a JASCO instrument model V-570. UV-visible measurements were done using X-ma 2000 spectrophotometer. The transmission electron microscopy (TEM) images were obtained on a Philips CM120. X-ray diffraction (XRD) measurement was performed with a Bruker D8/ Advance powder X-ray diffractometer. Atomic absorption analyses were conducted using a Shimadzu AA-6300 instrument. High resolution transmission electron microscopy (HR-TEM) was performed using a HR-TEM FEI TEC9G20 apparatus 
operated at $200 \mathrm{kV}$ accelerating voltage. Size distribution of CQDs were measured by DLS analysis on a HORIBALB550 instrument.

\subsection{Methods and materials}

All materials were provided from Merck or Sigma Aldrich and used as received without further purification. Echinops persicus plant was collected from around the city of Birjand- Shokat Abad in Southern Khorasan, Iran in April-May 2019. Rutin, DPPH (1, 1-diphenyl-2- picrylhydrazyl), Folin-Ciocalteau reagent, and ascorbic acid were purchased from Sigma and Merck companies. Gallic acid was purchased from Fluka supplier.

\subsection{Plant extraction}

The fresh and healthy parts of Echinops persicus (leaf, stem, root, and flower) were collected from around Birjand-Shokat Abad. After shade drying in a mixer, $5 \mathrm{~g}$ of each powdered plant sample was extracted with organic solvents with an increase of polarity at a ratio of 1: $15(\mathrm{v} / \mathrm{v})$. The extractions were performed by Maceration for the measurement of secondary metabolites.

\subsection{Measurement of phenolic compounds}

To prepare standard solutions, $0.01 \mathrm{~g}$ of gallic acid (1000 ppm) was dissolved in $10 \mathrm{ml}$ of $50 \% \mathrm{EtOH}$ and subsequently $0,20,40,60,80,100$ and 120 ppm gallic acid solutions were prepared (ESI, Fig. S1). Phenolic compounds were measured by a previously reported method by Škerget et al. [29, 30]. Briefly, $0.5 \mathrm{~mL}$ of diluted or standard sample, $2.5 \mathrm{~mL}$ of folin ciocalteu reagent $(10 \%)$ and $2 \mathrm{~mL}$ of sodium carbonate solution (7.5\%) were mixed in darkness at room temperature. After $1 \mathrm{~h}$ of the mixing, the absorbance of the solution was read at $760 \mathrm{~nm}$.

\subsection{Measurement of total flavonoid compounds}

To prepare standard solutions (routine solution $1000 \mathrm{ppm}$ ), $0.01 \mathrm{~g}$ of routine was dissolved in $10 \mathrm{~mL}$ of $50 \% \mathrm{EtOH}$ and subsequently, 10, 20, 40,60, 80, 100 and 120 ppm solutions were prepared. The flavonoid content was measured by a colorimetric method (ESI, Fig. S2), which is based on the formation of a flavonoid-aluminum complex with maximum absorption at $415 \mathrm{~nm}$ [31]. $1 \mathrm{~mL}$ of standard or extract was added to $1 \mathrm{~mL}$ of $\mathrm{AlCl}_{3} \cdot 6 \mathrm{H}_{2} \mathrm{O}$ solution. Then, $3 \mathrm{~mL}$ of $10 \%$ sodium acetate solution was added to the solution. After $40 \mathrm{~min}$, the absorbance of the solutions was recorded at $415 \mathrm{~nm}$. The experiments were performed for hexane, acetone, ethyl acetate, and water extract of flower, leaf, and root of Echinops persicus.

\subsection{Determination of total tannins content}

The tannins content of the plant was measured by the dissolution of $10 \mathrm{mg}$ of the desired organ powder to $4.0 \mathrm{~mL}$ of distilled water. The resulting solution is then divided into two portions and $1.0 \mathrm{~mL}$ of distilled water and $4.0 \mathrm{~mL}$ of Conc. $\mathrm{HCl}$, was added to each portion. Absorption of the first part was recorded after heating at $100^{\circ} \mathrm{C}$ for $30 \mathrm{~min}$. The absorbance of the second portion was read after the addition of $0.5 \mathrm{~mL}$ of ethanol at room temperature. The absorptions were measured at three different wavelengths of $470 \mathrm{~nm}, 520 \mathrm{~nm}$ and $570 \mathrm{~nm}$. The total amount of tannin (TTC in $\mathrm{g} \mathrm{L}^{-1}$ ) was calculated using the following formula (1-3) [32].

$\Delta A_{520}=1.1 \times \Delta A_{470}$

$\Delta A_{520}=1.57 \times \Delta A_{570}$

$\Pi T C=15.7 \times \operatorname{Min}\left(\Delta A_{520}\right)$

\subsection{Determination of alkaloids}

Analysis of alkaloids in the plant was performed according to the method described by Muthukrishnan and Manogaran [33]. To measure of alkaloid contents, $5.0 \mathrm{~g}$ of the dried plant powder (leaves and stems, roots, flowers) was extracted to $200 \mathrm{~mL}$ of ethanolic acetic acid $10 \%$ and set it aside for $4 \mathrm{~h}$ in dark. Then, the resultant solution was filtered by Whatman no. 1 filter paper, and the volume of the residue was reduced to one quarter by heating. After cooling to room temperature, a concentrated ammonia solution was added dropwise until sediment was formed. To make sure that the precipitate is an alkaloid, it was tested with Dragendorff's reagent. The interaction of alkaloid with Dragendorff's reagent on a TLC provides an orange spot, that indicates the presence of alkaloids. The resulting sediment was filtered with a Whatman no. 1 filter paper, dried into the oven, weighted and reported as alkaloid weight in the plant.

\subsection{Determination of saponins}

The content of saponins was determined by a previously reported method [34]. Briefly, $20 \mathrm{~g}$ of each part of the dried plant powder (leaves and stems, roots, flowers) was extracted to $200 \mathrm{~mL}$ of EtOH $20 \%$. The extraction was performed at reflux conditions for $4 \mathrm{~h}$. The resulting extracts were filtered and kept at $4{ }^{\circ} \mathrm{C}$. The total volume of the extract was concentrated to one quarter by heating. Then, the extracts were further extracted to diethyl ether 
$(3 \times 20 \mathrm{~mL})$ and then $n$-butanol $(3 \times 20 \mathrm{~mL})$. The organic layers were combined and washed with $\mathrm{NaCl}$ solution (5 wt\%). The solvent was removed and the resulting sediments were reported as saponins in the plant.

\subsection{Determination of anthocyanin}

Contents of anthocyanin in the Echinops persicus plant was measured based on a previously reported protocol [35]. Briefly, $0.1 \mathrm{~g}$ of the dry plant was placed in a mortar and rubbed and sanded with $10 \mathrm{~mL}$ of acidic methanol (MeOH: $\mathrm{HCl}$ (conc.) 1:99). Then, the extract was poured into the test tubes and incubated in the dark for $24 \mathrm{~h}$ at $25^{\circ} \mathrm{C}$. Then, it was centrifuged at $4000 \mathrm{rpm}$ for $10 \mathrm{~min}$ and the absorbance was recorded at $550 \mathrm{~nm}$. The concentration was calculated using the formula: $A=\varepsilon b c$, where $\varepsilon=33,000 \mathrm{M}^{-1} \mathrm{~cm}^{-1}$ and the results were reported in terms of $\mu \mathrm{mol}$ per gram of the plant.

\subsection{Determination of total carotenoids content}

To determine total carotenoid content (TCC), $10 \mathrm{~g}$ of plant sample (root, flower, or leaf) was extracted to acetone $80 \%$ $(100 \mathrm{~mL})$ and the resulting solution covered with an aluminum foil and stored at $4{ }^{\circ} \mathrm{C}$ for 3 days. Then the solution was filtered with a Whatman no. 1 filter paper. The absorption of the residue was recorded at three different wavelengths of 660,642 , and $470 \mathrm{~nm}$ and the desired TCC was measured by the following formula $[36,37]$ :

$C_{a}=12.25 A_{660}-2.79 A_{642}$

$C_{b}=21.50 A_{642}-5.10 A_{660}$

$C_{x+c}=\frac{1000 A_{470}-1.82 C_{a}-85.02 C_{b}}{198}$

where $C_{a}$ and $C_{b}$ are the concentrations of chlorophyll (a) and chlorophyll (b) in $\mu \mathrm{g} \mathrm{mg}^{-1}$ of the plant extract respectively, and $\mathrm{C}_{\mathrm{x}+\mathrm{c}}$ represents the total amount of carotenoids. The ratios of the specific absorption coefficients at $\lambda_{\max }$ in the blue to $\lambda_{\max }$ in the red for chlorophylls $a, b$ and average absorption coefficients $A_{1 \mathrm{~cm}}{ }^{1 \%}$ at $470 \mathrm{~nm}$ for total carotenoids in various solvents were inserted according to data reported elsewhere [36].

\subsection{Screening of radical scavenging activity by dot-blot 2,2-diphenyl-1-picrylhydrazyl (DPPH) staining method}

The radical scavenging activity of the plant extract was evaluated by a dot-blot DPPH staining method [38]. In this method, the experiment was performed on a silica gel impregnated with UV-fluorescence indicator $(5 \times 5 \mathrm{~cm}$ plate). DPPH and ascorbic acid were used as control and standard respectively. First, DPPH was spotted on the plate, then the extract was applied on the spot. The scavenging was monitored qualitatively by the color change of spot from purple (blank, no antioxidant activity) to yellow or white, indicating potent antioxidant activity of each extract.

\subsection{Determination of antioxidant potency of leaf extract by DPPH method}

The antioxidant activity of the plant extract was also measured quantitatively by a method developed by Blois using DPPH free radicals [38]. Briefly, various concentrations of water or ethanolic leaf extract were prepared, and for each experiment, $75 \mu \mathrm{L}$ plant extract was added to $3.9 \mathrm{~mL}$ of $0.00463 \mathrm{~g} / \mathrm{L}$ DPPH solution. The resulting solution was stirred for $30 \mathrm{~min}$ in a dark place. The absorbance of the solutions was recorded at $517 \mathrm{~nm}$. The inhibition percentage (IP) of the extract was calculated based on the following Eq. (7):

$\%$ Inhibition $=\frac{A_{\text {blank }}-A_{\text {sample }}}{A_{\text {blank }}} \times 100$

In this method, the color change of the solution from purple to yellow indicates the quenching of DPPH free radicals by the plant extract. Finally, $\left(\mathrm{IC}_{50}\right)$ was determined from the plot of \%IP versus concentration.

\subsection{Determination of metal ions in the plant organs}

The metal ions preset in various parts of the plant were determined by AAS from the ash prepared from burning the different parts of the plant.

\subsection{Green synthesis of carbon quantum dots (CQDs) from Echinops persicus plant}

CQDs were synthesized via a hydrothermal method [39] using all organs of Echinops persicus as the carbon source. Echinops persicus powder $(6.0 \mathrm{~g})$ was added to $75 \mathrm{~mL}$ distilled water, ultra-sonicated for $30 \mathrm{~min}$ at room temperature and then transferred to a $150 \mathrm{~mL}$ Teflon-lined autoclave. The autoclave was placed in the furnace for $10 \mathrm{~h}$ at $200^{\circ} \mathrm{C}$. To achieve outmost efficiency, extract concentration and calcination temperature as two effective parameters were also studied and optimized. 


\section{Results and discussion}

Figure 1 shows the phenolic, flavonoid, and tannin contents in various organs of Echinops persicus plant. Based on the results, the root of the plant has the most content of phenolic compounds. This content was major in acetone and ethanol extract (Fig. 1a). Ethanolic extract of the plant flower, showed the highest content of flavonoid and tannins (Fig. 1b, c). The aerial and root parts of the plant exhibited rather same results for flavonoid and tannin contents (Fig. 1b, c). The results also demonstrated that hexane and next ethyl acetate were the weak solvents for the extraction of phenol, flavonoid, and tannin content for Echinops persicus plant. Furthermore, these results suggest that the flower of the plant could be used as an efficient additive
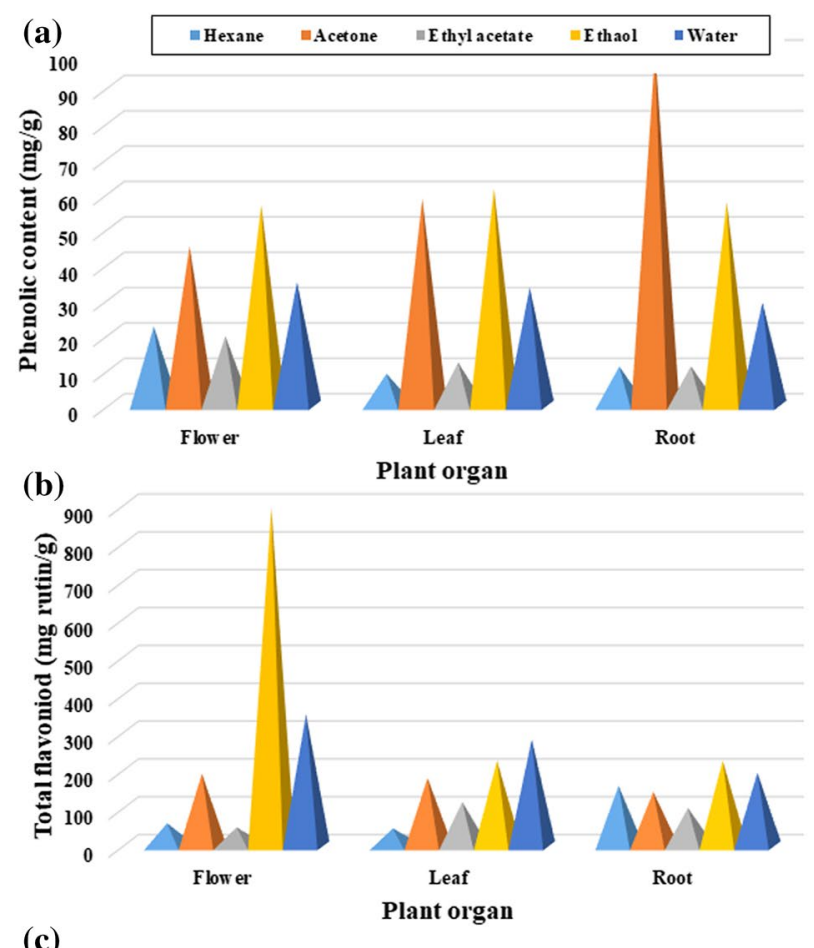

(c)

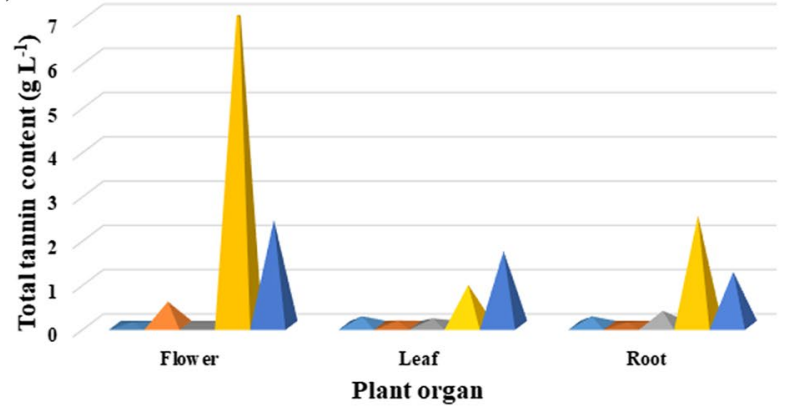

Fig. 1 Determination of a total phenolic, $\mathbf{b}$ total flavonoid, and $\mathbf{c}$ total tannin contents in the flower, leaf, and root of Echinops persicus plant in various extracts to drug compositions given that high biological activities [12].

Alkaloid, saponins, anthocyanin, and carotenoid content of the plant were determined in root, flower, and leaf of the plant (Fig. 2a-d). As shown in Fig. 2a, aerial parts of the plant contain the highest amount for alkaloid, anthocyanin, and carotenoids (Fig. 2c, d). The highest amount of saponins was found in the root extract $(0.7 \mathrm{~g} / 20 \mathrm{~g})$, however, other contents were lower than leaf or flower (Fig. 2b). The alkaloid values obtained for the different plant organs are shown in Fig. 2c.

Plants have been well known as bio-accumulator from contaminated soil and water. In this point of view, plants are the good evidence for the evaluation of soil nutrition. Moreover, the use of plants through phytoremediation technology is an alternative solution to treat heavy metal contaminated areas and can be used to remediate the environment [40]. Plants show different responses to different heavy metals exposure. Several plants are sensitive while other plants have a high tolerance to several heavy metals. As a consequence of plant-metal interaction, several plants accumulate heavy metals from the soil, which affects their growth and development. However, some plants have a high tolerance and can keep the growth and development even under heavy metals stress. Different responses of plants to heavy metals exposure depend on its level of heavy metals tolerance. For example, the presence of $\mathrm{Zn}$ can also change the chlorophyll a fluorescence and antioxidant system parameters [40-42]. So, the determination of heavy metals in the ash of a plant give valuable information about soil nutrition. Table 1 shows the results of the heavy metals present in ash of the flower, leaf, and root of Echinops persicus plant. Potassium was the major element in the flower and leaf of the plant. On the other hand, the root of the plant is a rich source of $\mathrm{Ca}$ and $\mathrm{Mn}$, which can be directly attributed to the soil. The results clearly indicated that the soil of Shokat Abad in Birjand (Southern Khorasan province) is in relatively good health.

\subsection{Antioxidant activity}

The ethanol and water extract of Echinops persicus was spotted on each row in which the color changes from purple to yellow or white was well observed, that indicating the potent antioxidant activity of the extract when compared to standard ascorbic acid. The results showed that the amount of antiradical activity depends on the type of solvent used for the extraction. The concentration of the extract does not have much effect on the antioxidant activity. The highest antioxidant properties are related to the aqueous and ethanolic extracts (Fig. 3).

After determining the maximum inhibitory effect on the aqueous and ethanolic extracts of the plant 


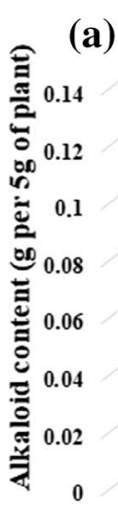

(c)

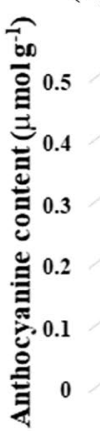

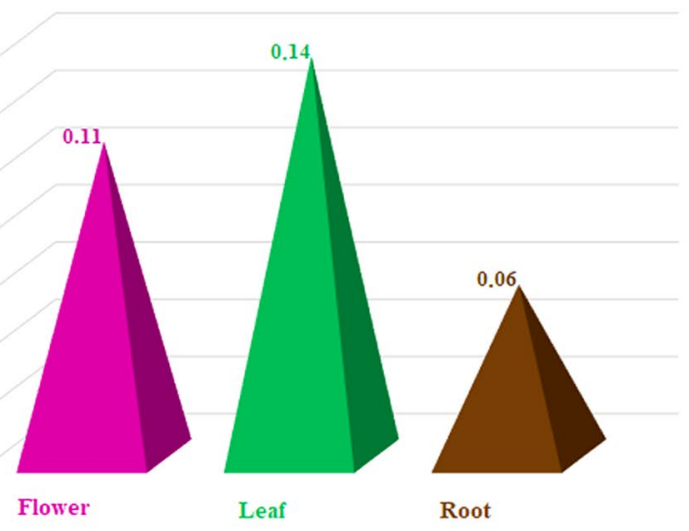

Plant organ

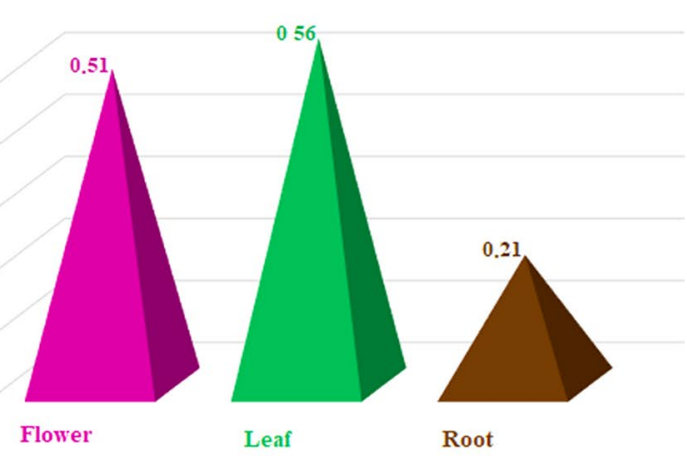

Plant organ

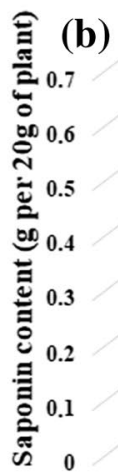

(d)

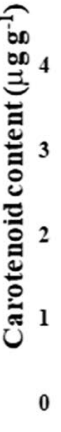

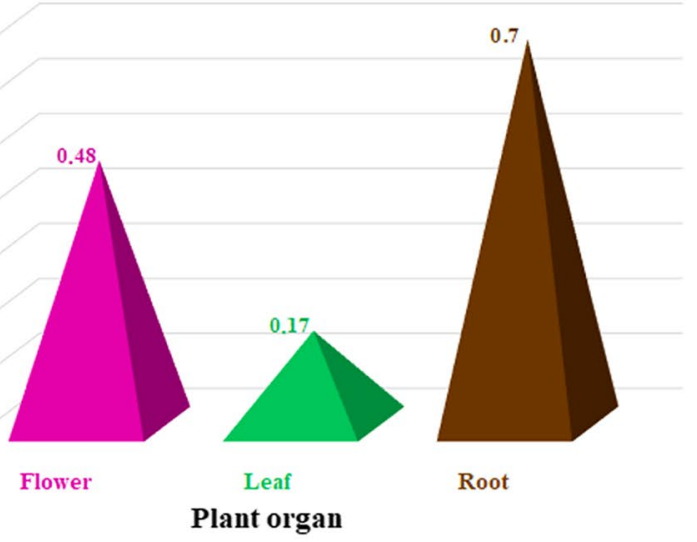

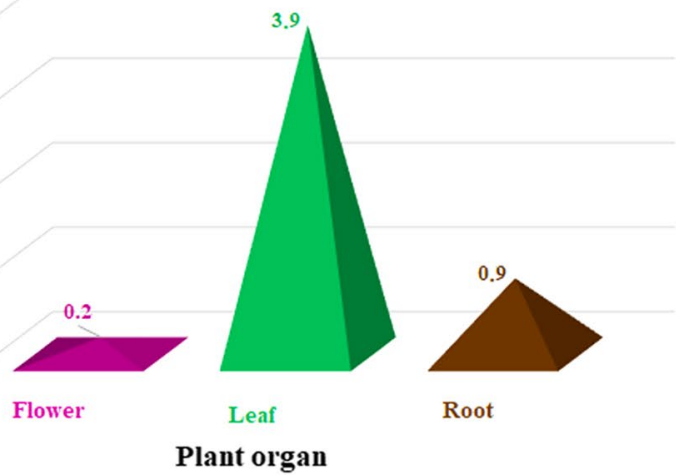

Fig. 2 a Alkaloid, b saponins, $\mathbf{c}$ anthocyanin and $\mathbf{d}$ carotenoid contents in leaf, flower and root of Echinops persicus plant

Table 1 Measurement of important heavy metals present in various parts of Echinops persicus plant

\begin{tabular}{lccccccrr}
\hline Organ & \multicolumn{2}{l}{ Metal content (ppm) } & & & & & \\
\cline { 2 - 8 } & $\mathrm{Na}$ & $\mathrm{Mg}$ & $\mathrm{Cu}$ & $\mathrm{Zn}$ & $\mathrm{Ca}$ & $\mathrm{Mn}$ & $\mathrm{Fe}$ & $\mathrm{K}$ \\
\hline Flower & 86.2 & 2.0 & 2.0 & 2.8 & 140.8 & 322.2 & 41.2 & 1849.0 \\
Leaf & 338.3 & 3.9 & 0.8 & 2.2 & 377.7 & 521.8 & 89.2 & 1691.6 \\
Root & 374.4 & 5.8 & 2.4 & 6.0 & 395.4 & 625.2 & 105.8 & 130.5 \\
\hline
\end{tabular}

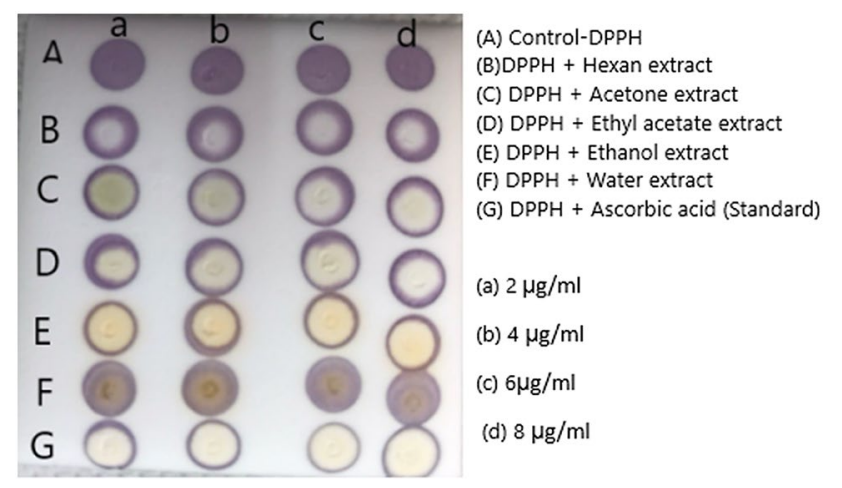

Fig. 3 The dot-blot assay of different extracts of Echinops persicus in the presence of DPPH

\section{SN Applied Sciences}

qualitatively, the inhibition percentage (\%Inhibition) of aqueous and ethanolic extracts of different plant organs at different concentrations was studied quantitatively. As shown in Fig. 4, aqueous extracts for flowers and roots contain more antioxidant compounds than aqueous extracts of aerial parts. Then, the concentration of plant extracts with a $50 \%$ radical scavenging percentage (i.e. $I C_{50}$ ) was calculated by the diagrams (Fig. $4 a-c$ ). Low $\mathrm{IC}_{50}$ indicates greater inhibition [43]. Accordingly, as shown in Fig. $4 \mathrm{~d}$, aqueous $\left(\mathrm{IC}_{50}=4.4\right)$ and ethanolic $\left(I C_{50}=5.0\right)$ extract of the root have the lowest $I C_{50}$ and consequently provide the highest inhibition. On the other hand, the plant flower extract has the least 

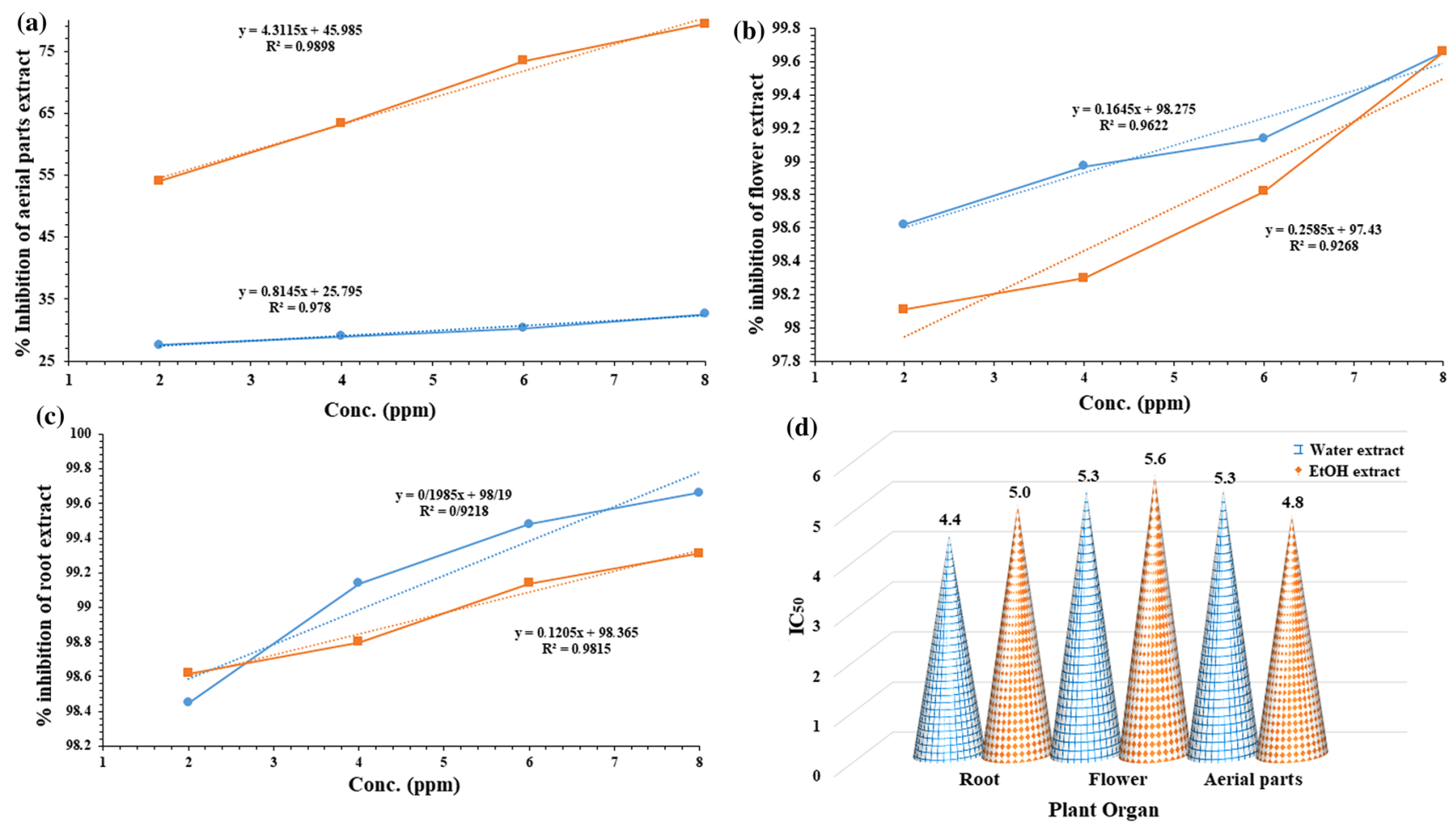

Fig. 4 Inhibition percentage of ethanol (orange curves) and water (blue curves) extracts of a aerial parts, $\mathbf{b}$ flower and $\mathbf{c}$ root extract of Echinops persicus. $\mathbf{d}$ Determination of $\mathrm{IC}_{50}$ for the plant organs

Table 2 Comparison of antioxidant activity of some plant species [44-46]

\begin{tabular}{lllc}
\hline Entry & Plant & Solvent extract & IC50 \\
\hline 1 & Entandrophragma angolense & EtOH & 18.39 \\
2 & Uapaca guineensis & $\mathrm{EtOH}$ & 25.59 \\
3 & Aegle marmelos & $\mathrm{EtOH}$ & 24.90 \\
4 & Green tea (Camellia sinensis) & $\mathrm{MeOH}$ & 6.7 \\
5 & Camellia sinensis linn & $\mathrm{MeOH}$ & 9.7 \\
6 & Piper cubeba Linn & $\mathrm{MeOH}$ & 11.3 \\
7 & Syzygium aromaticum & $\mathrm{MeOH}$ & 9.9 \\
\hline
\end{tabular}

amount of inhibition compared to other plant organs. In order to better understand the inhibitory effect of Echinops persicus plant, a comparison was made with several other plants.

As shown in Table 2, $\mathrm{IC}_{50}$ for Echinops persicus is comparable with green tea (Camellia sinensis) (Table 2, entry 4), Camellia sinensis linn (Table 2, entry 5), and Syzygium aromaticum (Table 2, entry 7). More importantly, Echinops persicus shows much higher inhibition activity than Entandrophragma angolense, Uapaca guineensis Aegle marmelos, Piper cubeba Linn (Table 2, entries 1-3, 6).

\subsection{Optimization of temperature and plant extract concentration over the synthesis of CQDs from Echinops persicus plant}

Two effective factors for the plant extract- mediated preparation of CQDs including temperature and concentration of the plant flower extract were screened. The concentration of $6 \mathrm{~g}$ of the plant sample in $75 \mathrm{~mL}$ distilled water provided the high intensity and subsequently a high amount of CQDs at $200^{\circ} \mathrm{C}$. With increase and/or decrease of the concentration, intensity decreased (Fig. 5). Then, the preparation of CQDs was evaluated at various calcination temperatures using a concentration of $6 \mathrm{~g} / 75 \mathrm{~mL}$. The highest possible efficiency was obtained at $200^{\circ} \mathrm{C}$ (Fig. 5). No improvement in efficiency was observed at higher and/ or lower temperatures.

The electronic spectrum of CQDs occurs due to the size of the nanoparticles. UV-Vis spectroscopy is, therefore, an efficient way to monitor the optical properties and quantum size of nanoparticles. CQDs have a relatively wide absorption spectrum, with $\lambda_{\max }=400-450 \mathrm{~nm}$ [47], which corresponds to the electronic transitions from the first excited level of CQDs. The maximum absorption of CQDs decreases with decreasing particle size. Accordingly, as shown in Fig. $5 \mathrm{a}$, the highest absorption was at concentration of $6 \mathrm{~g} / 75 \mathrm{~mL}$. The maximum absorption of CQDs 

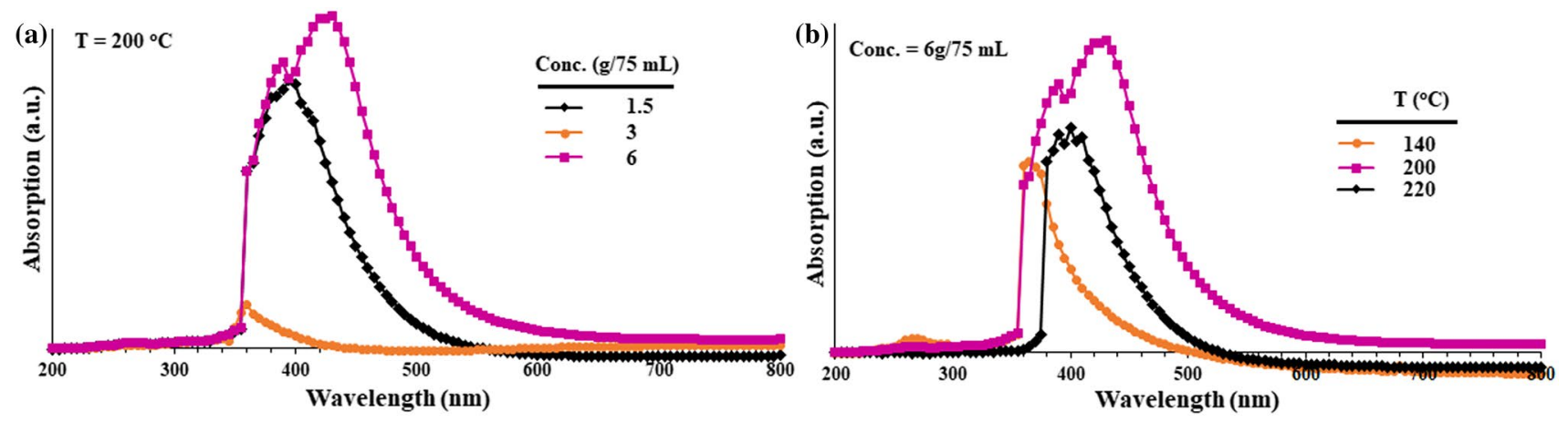

Fig. 5 Optimization of $\mathbf{a}$ concentration of the plant flower extract and $\mathbf{b}$ temperature for the preparation of CQDs

decreases with decreasing particle size [47], thus the size of NPs decreasing sharply at lower concentrations. Temperature also had an inevitable effect on the preparation of CQDs. Increasing the temperature to $200^{\circ} \mathrm{C}$, increases the amount of nanoparticles produced (Fig. 5b). As the temperature increases, the absorption peak shifts to lower wavelengths, resulting in a decrease in the size of the nanoparticles.

The images in Fig. 6 show the as-prepared CQDs using flower extract of Echinops persicus under natural and UV (325 mn) light. There is a relationship between the color of CQDs under ultraviolet light and their sizes [48, 49]. From the green color of CQDs, it can be estimated that the size of the synthesized CQDs is between 3.5 and $5.5 \mathrm{~nm}$.

\subsection{Characterization of CQDs}

With premium conditions in hand, for comparison, CQDs were obtained from leaf and root in addition to flower extract. FTIR spectra obtained from various parts of the plant were shown in Fig. 7. Almost the same spectra were observed for all of the sources. A broad peak at $3300 \mathrm{~cm}^{-1}$ was related to hydroxyl groups stretching vibrations [26, 27]. A peak appeared at $\sim 2930 \mathrm{~cm}^{-1}$ represent the $\mathrm{C}-\mathrm{H}$ stretching bond as a main characteristic bond for CQDs [50]. Also, a series of peaks around 1604 and $1650 \mathrm{~cm}^{-1}$ were assigned to $C=C$ and $C=0$ bonds respectively. $A$ peak with medium intensity represents the $\mathrm{C}-\mathrm{O}$ bond, which along with previous vibrations confirmed the presence of carboxylic groups [28].

The UV spectrum of CQDs indicates that the size of the flower-derived CQDs is more homogeneous than the other CQDs produced by root or aerial parts, which the deviation from the shape is very low (Fig. 7B) [51].

Figure $7 C$ shows the emission spectrum of the CQDs, that the range of 500-550 nm shows the major absorption corresponding to the green wavelength region. These emission zones are related to the photon emission resulting from the electron-hole hybrid rearrangement. The particle size distribution affects the fluorescence absorption bandwidth, and therefore the more uniform particles give the narrower particle size distribution with a symmetrical fluorescence absorption. On the other hand, the greater particle distribution, provide the wider absorption. Accordingly, the CQDs synthesized by the plant are homogeneous in morphology and in addition, as shown in the figure, the highest color intensity is related to the plant root (Fig. 7C).

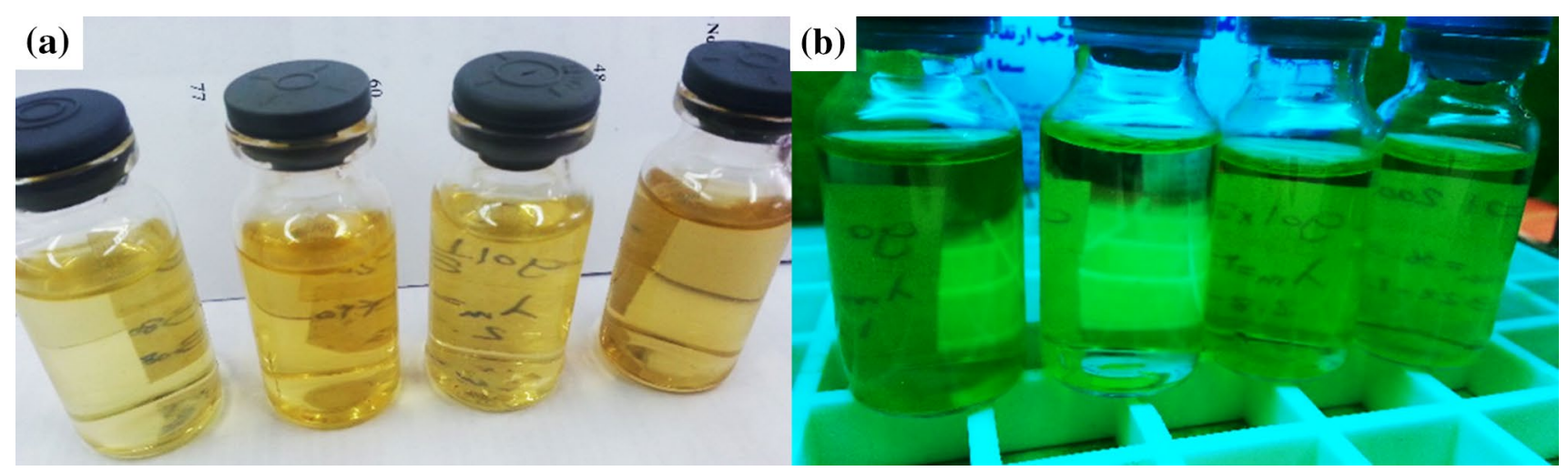

Fig. 6 Images from the as-prepared CQDs from flower extract of Echinops persicus under a natural light and b UV light (325 nm) 

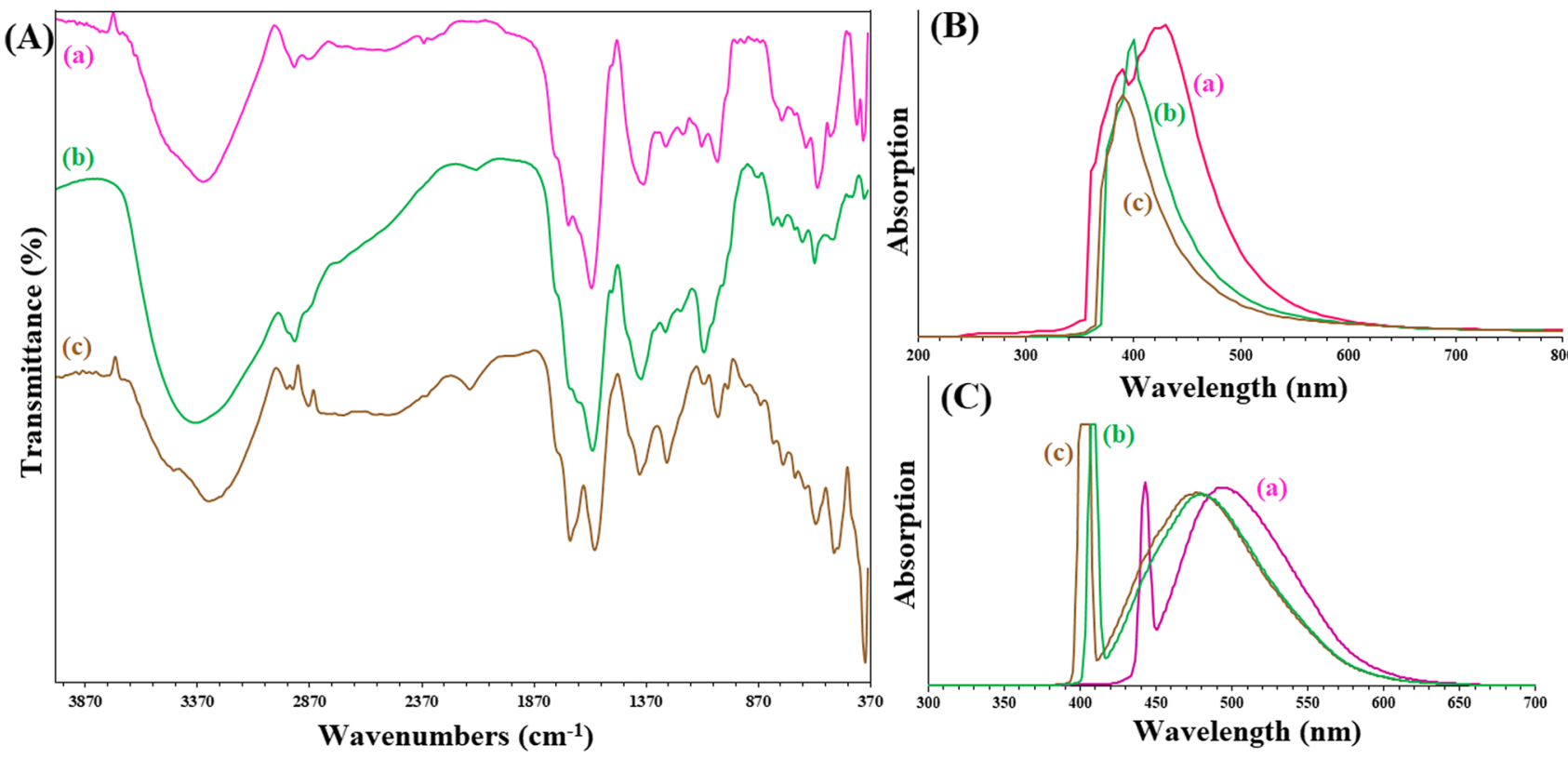

Fig. 7 A FTIR, B UV-Vis and C fluorescence spectra of CQDs prepared from (a) flower, (b) leaf, and (c) root of Echinops persicus respectively

X-ray diffraction of the as-prepared CQDs was shown in Fig. 8a. An amorphous peak at $2 \theta=23^{\circ}$ corresponds to the characteristic peak for CQDs in agreement with the literature $[50,52]$. Note to the presence of $\mathrm{Mg}$ in CQDs structure, the sharp crystalline peak at $2 \theta=29^{\circ}$ represents the presence of $\mathrm{MgO}$ microcrystals according to the literature [53]. However, the overall pattern of the CQDs has good math with $\mathrm{KCl}$ sylvite crystal structure [54]. Various elements were detected in the CQDs (Fig. 8b). As expected, major elements were $\mathrm{C}$ and $\mathrm{O}$ with $40.47 \mathrm{wt} \%$ and $40.51 \mathrm{wt} \%$ respectively, confirmed the preparation of CQDs. Other elements with an abundance of 3-4 wt\% were $\mathrm{Mg}, \mathrm{K}$, an Cl.

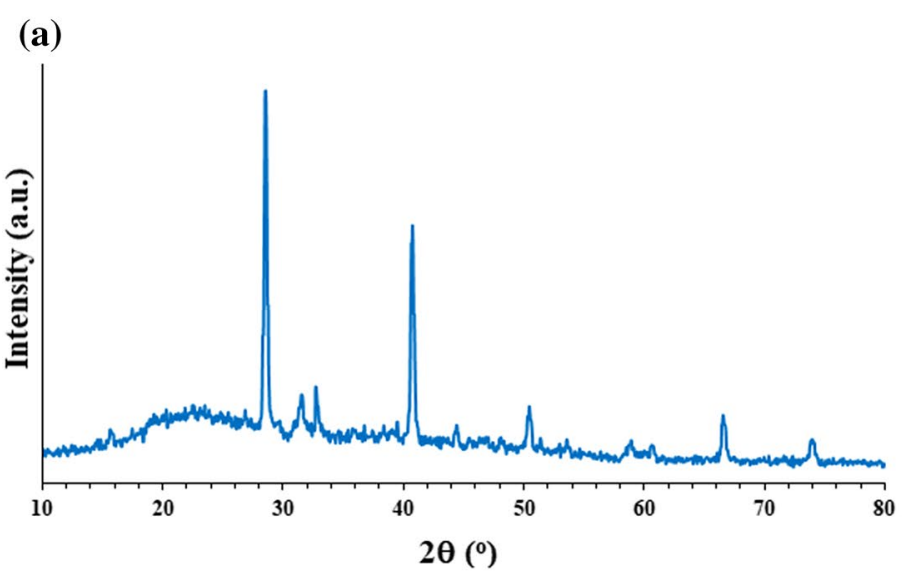

TEM images of the prepared CQDs confirmed the homogenous distribution and morphology of the NPs. Also, from the images, size of the NPs is between 4-6 nm (Fig. 9). The larger-scale image of the nanoparticles (Fig. 9, right image) also shows a regular shrub structure of the particles (Fig. 9a).

HR-TEM image from CQDs was also confirmed their homogeneous and spherical shapes. As shown in Fig. 9 (inset image), the nanoparticles have a homogeneous dispersion spherical shape with a size of about 5-6 $\mathrm{nm}$. The lattice fringe spacing indicated in the HR-TEM image is $0.222 \mathrm{~nm}$, completely in agreement with the (100) spacing reported for CQDs [55].

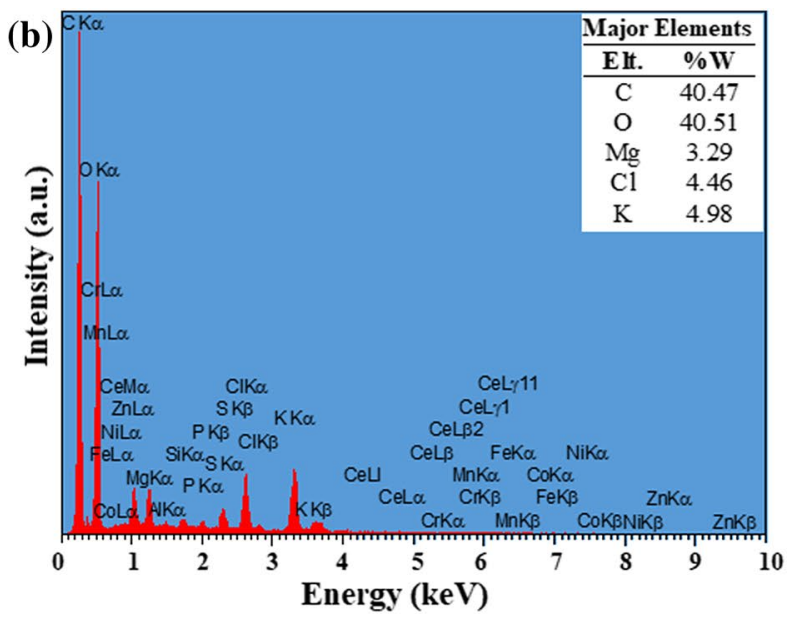

Fig. 8 a XRD pattern and $\mathbf{b}$ EDX analysis of the as-prepared CQDs using flower of Echinops persicus 

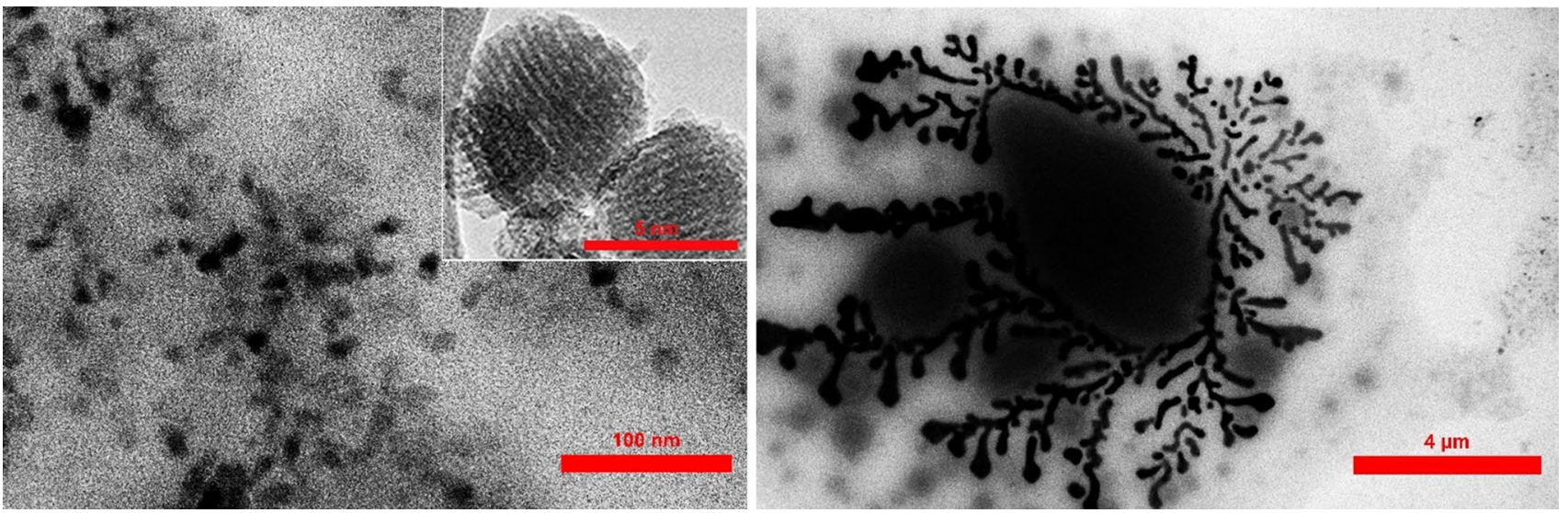

Fig. 9 TEM, and HRTEM (inset image) images of the as-prepared CQDs using flower extract of Echinops persicus

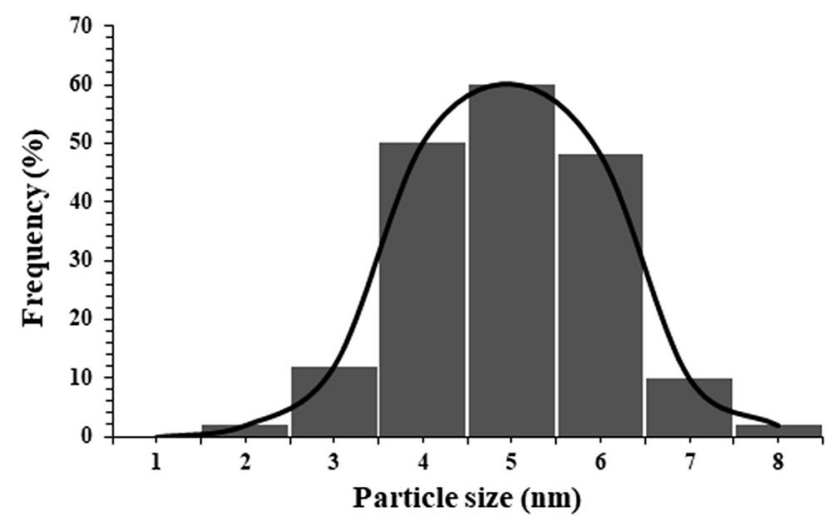

Fig. 10 Size histogram of the bio-synthesized CQDs using flower extract of Echinops persicus

Also, particle size distributions of CQDs revealed a uniform distribution with an average particle size of 4-6 nm, in excellent agreement with TEM, HRTEM, and XRD results (Fig. 10).

\section{Conclusion}

Phytochemical studies on Echinops persicus plant revealed that the plant is a rich source of tannins, anthocyanins, phenol, and flavonoid contents. The major phenolic and flavonoid content was found in the root acetone and flower ethanolic extract of the plant as $90 \mathrm{mg} / \mathrm{g}$ and $893 \mathrm{mg}$ rutin/g respectively. Also, phytochemical screening of the plant extracts showed the presence of tannins, anthocyanins, and alkaloids as $7.6 \mathrm{~g} / \mathrm{L}, 0.56 \mu \mathrm{mol} / \mathrm{g}$, and $0.14 \mathrm{~g} / 5 \mathrm{~g}$, respectively for flower and leaf extracts. Also, major saponins and carotenoid contents were found in root and leaf of the plant as $0.7 \mathrm{~g} / 20 \mathrm{~g}$ and $3.9 \mu \mathrm{g} / \mathrm{g}$ respectively. An excellent and acceptable antioxidant activity was found for the plant. The largest capacity to neutralize DPPH radicals was found for root water extract of Echinops persicus plant that found to be $\mathrm{IC}_{50}=4$.4. Finally, as a green protocol, carbon quantum dots were successfully prepared by $6 \mathrm{~g} / 75 \mathrm{~mL}$ of plant extract of Echinops persicus at $200^{\circ} \mathrm{C}$. As-prepared CQDs were characterized by XRD, TEM, HRTEM, EDX, FTIR, and UV-Vis analyses. The prepared NPs have a mean size of 3-5 $\mathrm{nm}$ with a homogeneous spherical morphology.

Acknowledgements The authors are thankful to Research Council of University of Birjand for providing all the necessary facilities to carry out the research work.

\section{Compliance with ethical standards}

Conflict of interest The authors declare that they have no competing interests.

\section{References}

1. Kumaran A, Karunakaran J (2007) In vitro antioxidant activities of methanol extracts of five Phyllanthus species from India. LWTFood Sci Technol 40:344-352

2. Bonarska-Kujawa D, Cyboran S, Oszmiański J, Kleszczyńska H (2011) Extracts from apple leaves and fruits as effective antioxidants. J Med Plants Res 5:2339-2347

3. Zangeneh $M M$, Zangeneh A, Tahvilian R, Moradi R, Zhaleh H, Amiri-Paryan A, Bahrami E (2018) Hepatoprotective and hematoprotective effects of Falcaria vulgaris aqueous extract against $\mathrm{CCl} 4$-induced hepatic injury in mice. Comp Clin Pathol 27:1359-1365

4. Moradi R, Hajialiani M, Salmani S, Almasi M, Zangeneh A, Zangeneh MM (2019) Effect of aqueous extract of Allium saralicum RM Fritsch on fatty liver induced by high-fat diet in Wistar rats. Comp Clin Pathol 28:1205-1211

5. Zangeneh MM, Goodarzi N, Zangeneh A, Tahvilian R, Najafi F (2018) Amelioration of renal structural changes in STZ-induced

\section{SN Applied Sciences}


diabetic mice with ethanolic extract of Allium saralicum RM Fritsch. Comp Clin Pathol 27:861-867

6. Zangeneh MM, Zangeneh A, Tahvilian R, Moradi R (2018) Antidiabetic, hematoprotective and nephroprotective effects of the aqueous extract of Falcaria vulgaris in diabetic male mice. Arch Bio Sci 70:655-664

7. Hagh-Nazari L, Goodarzi N, Zangeneh MM, Zangeneh A, Tahvilian R, Moradi R (2017) Stereological study of kidney in streptozotocin-induced diabetic mice treated with ethanolic extract of Stevia rebaudiana (bitter fraction). Comp Clin Pathol 26:455-463

8. Mohseni S, Sani AM, Tavakoli M, Raoufi AM (2017) Effect of extraction conditions on antioxidant activities of Echinops persicus. J Essent Oil-Bear Plants 20:1633-1644

9. Rad AA, Najafzadeh-Varzi H, Farajzadeh-Sheikh A (2010) Evaluation of anti-ulcer activity of Echinops persicus on experimental gastric ulcer models in rats. Vet Res Forum 1:188-191

10. Grauso L, Yegdaneh A, Sharifi M, Mangoni A, Zolfaghari B, Lanzotti V (2019) Molecular networking-based analysis of cytotoxic saponins from sea cucumber Holothuria atra. Mar Drugs 17:86

11. Zhu Z, Wen Y, Yi J, Cao Y, Liu F, McClements DJ (2019) Comparison of natural and synthetic surfactants at forming and stabilizing nanoemulsions: tea saponin, Quillaja saponin, and Tween 80. J Colloid Interface Sci 536:80-87

12. Švecová $M$, Ulbrich $P$, Dendisová $M$, Matějka $P$ (2018) SERS study of riboflavin on green-synthesized silver nanoparticles prepared by reduction using different flavonoids: what is the role of flavonoid used? Spectrochim Acta Part A 195:236-245

13. Wang H, Li J, Tao W, Zhang X, Gao X, Yong J, Zhao J, Zhang L, Li Y, Duan JA (2018) Lycium ruthenicum studies: molecular biology, Phytochemistry and pharmacology. Food Chem 240:759-766

14. Güy N, Özacar M (2018) Visible light-induced degradation of indigo carmine over $\mathrm{ZnFe}_{2} \mathrm{O}_{4} / \mathrm{Tannin} / \mathrm{ZnO}$ : role of tannin as a modifier and its degradation mechanism. Int J Hydrog Energy 43:8779-8793

15. Khanbabaee K, van Ree T (2001) Tannins: classification and definition. Nat Prod Rep 18:641-649

16. Milani A, Basirnejad M, Shahbazi S, Bolhassani A (2017) Carotenoids: biochemistry, pharmacology and treatment. Br J Pharmacol 174:1290-1324

17. Goula AM, Ververi M, Adamopoulou A, Kaderides K (2017) Green ultrasound-assisted extraction of carotenoids from pomegranate wastes using vegetable oils. Ultrason Sonochem 34:821-830

18. Zangeneh MM, Bovandi S, Gharehyakheh S, Zangeneh A, Irani $P$ (2019) Green synthesis and chemical characterization of silver nanoparticles obtained using Allium saralicum aqueous extract and survey of in vitro antioxidant, cytotoxic, antibacterial and antifungal properties. Appl Organomet Chem 33:e4961

19. Seydi N, Mahdavi B, Paydarfard S, Zangeneh A, Zangeneh MM, Najafi F, Jalalvand AR, Pirabbasi E (2019) Preparation, characterization, and assessment of cytotoxicity, antioxidant, antibacterial, antifungal, and cutaneous wound healing properties of titanium nanoparticles using aqueous extract of Ziziphora clinopodioides Lam leaves. Appl Organomet Chem 33:e5009

20. Shahriari M, Hemmati S, Zangeneh A, Zangeneh MM (2019) Biosynthesis of gold nanoparticles using Allium noeanum Reut. ex Regel leaves aqueous extract; characterization and analysis of their cytotoxicity, antioxidant, and antibacterial properties. Appl Organometal Chem 33:5189

21. Tahvilian $\mathrm{R}$, Zangeneh MM, Falahi $\mathrm{H}$, Sadrjavadi $\mathrm{K}$, Jalalvand $A R$, Zangeneh A (2019) Green synthesis and chemical characterization of copper nanoparticles using Allium saralicum leaves and assessment of their cytotoxicity, antioxidant, antimicrobial, and cutaneous wound healing properties. Appl Organometal Chem 33:e5234

22. Nasseri MA, Shahabi M, Allahresani A, Kazemnejadi M (2019) Eco-friendly biosynthesis of silver nanoparticles using aqueous solution of Spartium junceum flower extract. Asian J Green Chem 3:382-390

23. Janus $\measuredangle$, Piątkowski M, Radwan-Pragłowska J, Bogdał D, Matysek D (2019) Chitosan-based carbon quantum dots for biomedical applications: synthesis and characterization. Nanomaterials 9:274

24. Mallakpour S, Behranvand V (2018) Synthesis of mesoporous recycled poly (ethylene terephthalate)/MWNT/carbon quantum dot nanocomposite from sustainable materials using ultrasonic waves: application for methylene blue removal. J Cleaner Prod 190:525-537

25. Lim SY, Shen W, Gao Z (2015) Carbon quantum dots and their applications. Chem Soc Rev 44:362-381

26. Huang C, Dong H, Su Y, Wu Y, Narron R, Yong Q (2019) Synthesis of carbon quantum dot nanoparticles derived from byproducts in bio-refinery process for cell imaging and in vivo bioimaging. Nanomaterials 9:387

27. Kavitha T, Kumar S (2018) Turning date palm fronds into biocompatible mesoporous fluorescent carbon dots. Sci Rep 8:16269

28. Wang J, Qiu J (2016) A review of carbon dots in biological applications. J Mater Sci 51:4728-4738

29. Škerget $M$, Kotnik $P$, Hadolin $M$, Hraš $A R$, Simonič $M$, Knez Ž (2005) Phenols, proanthocyanidins, flavones and flavonols in some plant materials and their antioxidant activities. Food Chem 89:191-198

30. Tulipani S, Mezzetti B, Capocasa F, Bompadre S, Beekwilder J, De Vos CR, Capanoglu E, Bovy A, Battino M (2008) Antioxidants, phenolic compounds, and nutritional quality of different strawberry genotypes. J Agric Food Chem 56:696-704

31. Xi J, Yan L (2017) Optimization of pressure-enhanced solid-liquid extraction of flavonoids from Flos Sophorae and evaluation of their antioxidant activity. Sep Purif Technol 175:170-176

32. Hosu A, Cristea VM, Cimpoiu C (2014) Analysis of total phenolic, flavonoids, anthocyanins and tannins content in Romanian red wines: prediction of antioxidant activities and classification of wines using artificial neural networks. Food Chem 150:113-118

33. Muthukrishnan S, Manogaran P (2018) Phytochemical analysis and free radical scavenging potential activity of Vetiveria zizanioides Linn. J Pharmacogn Phytochem 7:1955-1960

34. Obadoni BO, Ochuko PO (2002) Phytochemical studies and comparative efficacy of the crude extracts of some haemostatic plants in Edo and Delta States of Nigeria. Glob J Pure Appl Sci 8:203-208

35. Wagner GJ (1979) Content and vacuole/extravacuole distribution of neutral sugars, free amino acids, and anthocyanin in protoplasts. Plant Physiol 64:88-93

36. Noureen $S$, Noreen $S$, Ghumman SA, Batool F, Arshad M, Noreen F, Ishtiaq U, Bukhari SNA (2018) Seeds of giant dodder (Cuscuta reflexa) as a function of extract procedure and solvent nature. Not Bot Horti Agrobot Cluj-Napoca 46:653-662

37. Harmut A (1987) Chlorophylls and carotenoids: pigments of photosynthetic membranes. Methods Enzymol 148:350-383

38. Blois MS (1958) Antioxidant determinations by the use of a stable free radical. Nature 181:1199

39. Jiang X, Qin D, Mo G, Feng J, Yu C, Mo W, Deng B (2019) Ginkgo leaf-based synthesis of nitrogen-doped carbon quantum dots for highly sensitive detection of salazosulfapyridine in mouse plasma. J Pharm Biomed Anal 164:514-519

40. Golan-Goldhirsh A (2006) Plant tolerance to heavy metals, a risk for food toxicity or a means for food fortification with essential metals: the Allium schoenoprasum model. In: Soil and water pollution monitoring, protection and remediation. Springer, Dordrecht, pp 479-486

41. Dasgupta S, Satvat PS, Mahindrakar AB (2011) Ability of Cicer arietinum (L.) for bioremoval of lead and chromium from soil. Int J Res Eng Technol Syst 24:338-341 
42. Tiecher TL, Ceretta CA, Ferreira PA, Lourenzi CR, Tiecher T, Girotto E, Nicoloso FT, Soriani HH, De Conti L, Mimmo T, Cesco S (2016) The potential of Zea mays $L$. in remediating copper and zinc contaminated soils for grapevine production. Geoderma 262:52-61

43. Nanaei M, Nasseri MA, Allahresani A, Kazemnejadi M (2019) Phoenix dactylifera L. extract: antioxidant activity and its application for green biosynthesis of Ag nanoparticles as a recyclable nanocatalyst for 4-nitrophenol reduction. SN Appl Sci 1:853

44. Khalaf NA, Shakya AK, Al-Othman A, El-Agbar Z, Farah H (2008) Antioxidant activity of some common plants. Turk J Biol 32:51-55

45. Perumal A, Krishna S, Madhusree M (2018) GC-MS analysis, antioxidant and antibacterial activities of ethanol extract of leaves of Aegle marmelos (L.) Corrãša. J Drug Deliv Ther 8:247-255

46. Offoumou MR, Kipre GR, Kigbafori DS, Camara D, Djaman AJ, Zirihi GN (2018) In vitro/ex vivo antiplasmodial activity and phytochemical screening of crude extracts Entandrophragma angolense (Welw.) C. DC., Griffonia simplicifolia (Vahl ex DC.) Baill. et Uapaca guineensis Müll. Arg. three plants of Ivorian pharmacopeia in treatment of malaria. Int J Curr Microbiol Appl Sci 7:2088-2095

47. Ye Q, Yan F, Luo Y, Wang Y, Zhou X, Chen L (2017) Formation of $\mathrm{N}$ S-codoped fluorescent carbon dots from biomass and their application for the selective detection of mercury and iron ion. Spectrochim Acta Part A 173:854-862

48. Feng H, Qian Z (2018) Functional carbon quantum dots: a versatile platform for chemosensing and biosensing. Chem Rec 18:491-505

49. Watson $A$, Wu X, Bruchez M (2003) Lighting up cells with quantum dots. Biotechniques 34:296-303
50. Shahshahanipour M, Rezaei B, Ensafi AA, Etemadifar Z (2019) An ancient plant for the synthesis of a novel carbon dot and its applications as an antibacterial agent and probe for sensing of an anti-cancer drug. Mater Sci Eng C Mater 98:826-833

51. Nasseri M, Behravesh S, Allahresani A, Kazemnejadi M (2019) Green synthesis of silver and magnetite nanoparticles using Cleome heratensis (Capparaceae) plant extract. Org Chem Res 5:190-201

52. Sharma S, Mehta SK, Ibhadon AO, Kansal SK (2019) Fabrication of novel carbon quantum dots modified bismuth oxide $\left(\mathrm{a}-\mathrm{Bi}_{2} \mathrm{O}_{3} / \mathrm{C}\right.$ dots): material properties and catalytic applications. J Colloid Interface Sci 533:227-237

53. Ponraj R, Kannan AG, Ahn JH, Kim DW (2016) Improvement of cycling performance of lithium-sulfur batteries by using magnesium oxide as a functional additive for trapping lithium polysulfide. ACS Appl Mater Interfaces 8:4000-4006

54. Li E, Du Z, Yuan S, Cheng F (2015) Low temperature molecular dynamic simulation of water structure at sylvite crystal surface in saturated solution. Miner Eng 83:53-58

55. Linehan K, Doyle H (2014) Efficient one-pot synthesis of highly monodisperse carbon quantum dots. RSC Adv 4:18-21

Publisher's Note Springer Nature remains neutral with regard to jurisdictional claims in published maps and institutional affiliations. 